\title{
Troubleshooting of Matrix Frequency Converter Conducted and Radiated Emissions
}

\author{
Gundars Asmanis, Riga Technical University, Leonids Ribickis, Riga Technical University, \\ Vladimirs Novikovs, Riga Technical University
}

\begin{abstract}
Matrix converter inherently exhibits sinusoidal input current waveforms and has less stressful output voltage waveforms, but it is causing problems with conducted and radiated emissions. This paper deals with matrix converter emitted disturbances from point of view of electromagnetic compatibility (EMC) standard EN61800-3 and allocates the sources of undesirable emissions using standard equipment used for EMC assessment according to variety international EMC standards and discusses methodology of troubleshooting flow, using low cost equipment available in almost every laboratory of Industrial Electronics and Electrical Engineering.
\end{abstract}

Keywords: conducted emissions, EMC, radiated emission, matrix frequency converter, troubleshooting

\section{INTRODUCTION}

In power electronic equipment, energy is converted from one form to another through power switching devices for different applications. On the other hand, electromagnetic interference (EMI) is brought out accompanying switching actions. To achieve a good electromagnetic compatibility (EMC) performance- comply with applicable EMC standards, trial and error method is often used to deal with these EMC issues, although it is very time consuming and depends much on experience. Studies on EMI in power electronic equipment are needed to remedy these EMI faults. It is commonly known that high values $\mathrm{dv} / \mathrm{dt}$ and $\mathrm{di} / \mathrm{dt}$ are the main sources of disturbances in power electronic equipment. In the control circuit, besides dv/dt and di/dt of power semiconductors in the main circuit, driving pulses, clock pulses, and so on may also cause EMI to some extent. In order to diagnose EMI sources and prevent disturbance propagation, it is necessary to study the propagation path characteristics of EMI. The general method is simulation of the whole circuit based on parasitic parameter extraction [1], [2].This method analyzes simple PCBs, including all components- passive, active and parasitic elements between them- stray capacitance, mutual inductance etc. While for a complete system or even part of it, it is very difficult to extract parasitic parameters of the control circuit with a large number of digital and analog ICs, it's getting worth if it's necessary to extract the parameters in complex three-dimensional structure.

Matrix converters are complex hybrid devices, which are becoming ubiquitous in many large scale industrial energy conversion applications. Due to their high complexity, the dynamic behavior is typically neglected at the controller design stage and usually only the (quasi) static behavior is concerned. However, since the increasing demands on harmonic generation and EMI requirements, it is mandatory to comply with related standards such as IEC 61800 "Adjustable speed electrical power drive systems" which appoint to take in account conducted and radiated emissions [3]. EMC measurements are carried out on a $3 \mathrm{~kW}$ matrix converter prototype designed without EMC concerns, created in Riga Technical University institute of Industrial Electronics and Electrical Engineering, covering the following aspects: conducted and radiated emission measurements according to international standards, EMI sources in matrix converter.

\section{APPLICABLE STANDARD IEC 61800-3, SCOPE AND EMISSION LIMITS}

Matrix converter is covered by IEC 61800-3 standard, as it is expected to utilize it as frequency converter for asynchronous drives. This part of IEC 61800 specifies electromagnetic compatibility requirements for power drive systems. A power drive system is defined, as system, that consists of a complete drive module and motor, whether a.c or d.c. Requirements are stated for power drive systems with converter input and/or output voltages (line-to-line voltage), up to $35 \mathrm{kV}$ a.c. r.m.s.

Power drive systems covered by this standard are those expected to install in residential, commercial and industrial locations with the exception of traction applications, and electric vehicles. Power drive systems may be connected to either industrial or public power distribution networks. Industrial networks are supplied by a dedicated distribution transformer, which is usually adjacent to or inside the industrial location, and supplies only industrial customers. Industrial networks can also be supplied by their own electric generating equipment. On the other hand, power drive systems can be directly connected to low-voltage public mains networks which also supply domestic premises, and in which the neutral is generally earthed (grounded).

The scope of third part of IEC 61800, related to EMC, includes a broad range of power drive systems, from a few hundred watts to hundreds of megawatts. The system aspect is not covered by this standard, but guidance is provided in the informative annexes. The requirements have been selected so as to ensure EMC for power drive systems at residential, commercial and industrial locations. The requirements cannot, however, cover extreme cases which may occur with an extremely low probability. Changes in the EMC behavior of a power drive systems, as a result of fault conditions, are not taken into account. 
The object of this standard is to define the limits and test methods for a power drive systems, according to its intended use, it includes immunity requirements and requirements for electromagnetic emissions.

Low-frequency emission requirements are given according to the nature of the supply network. High-frequency emission requirements are given according to four categories of intended use, which cover both environment and bringing into operation. As a product standard, this standard may be used for the assessment of power drive systems. It may also be used for the assessment of complete drive module or basic drive module, which can be marketed separately.

This standard does not specify any safety requirements for the equipment such as protection against electric shocks, insulation co-ordination and related dielectric tests, unsafe operation, or unsafe consequences of a failure. It also does not cover safety and functional safety implications of electromagnetic phenomena.

The emission limits in Table I and Table II are stated according to the following categories of power drive systems:

- C1- power drive systems of rated voltage less than $1000 \mathrm{~V}$, intended for use in first environment;

- C2- power drive systems of rated voltage less than $1000 \mathrm{~V}$, which is neither a plug in device nor a movable device and, when used in the first environment, is intended to be installed and commissioned only by professional;

- C3- power drive systems of rated voltage less than $1000 \mathrm{~V}$, intended for use in second environment and not intended for use in first environment;

- C4- power drive systems rated voltage equal to or above $1000 \mathrm{~V}$, intended for use in second environment.

TABLE I

LIMITS FOR MAINS TERMINAL DISTURBANCE VOLTAGE

\begin{tabular}{|c|c|c|c|c|}
\hline & \multicolumn{2}{|c|}{ Category C1 } & \multicolumn{2}{c|}{ Category C2 } \\
\hline $\begin{array}{c}\text { Frequency } \\
\text { band } \mathrm{MHz}\end{array}$ & $\begin{array}{c}\text { Quasi peak } \\
\mathrm{dBuV}\end{array}$ & $\begin{array}{c}\text { Average } \\
\mathrm{dBuV}\end{array}$ & $\begin{array}{c}\text { Quasi } \\
\text { peak } \\
\mathrm{dBuV}\end{array}$ & $\begin{array}{c}\text { Average } \\
\mathrm{dBuV}\end{array}$ \\
\hline $0,15 \leq \mathrm{f} \leq 0,5$ & $\begin{array}{c}66 \\
\text { decreases } \\
\text { logarithmic } \\
56\end{array}$ & $\begin{array}{c}56 \\
\text { decrease } \\
\text { logarithmic } \\
46\end{array}$ & 79 & 66 \\
\hline $0,5 \leq \mathrm{f} \leq 5$ & 56 & 46 & 73 & 60 \\
\hline $5 \leq \mathrm{f} \leq 30$ & 60 & 50 & 73 & 60 \\
\hline
\end{tabular}

TABLE II

LIMITS FOR MAINS TERMINAL DISTURBANCE VOLTAGE

\begin{tabular}{|c|c|c|c|}
\hline & & \multicolumn{2}{|c|}{ Category C3 } \\
\hline $\begin{array}{c}\text { Size of } \\
\text { system }\end{array}$ & $\begin{array}{c}\text { Frequency } \\
\text { band } \mathrm{MHz}\end{array}$ & $\begin{array}{c}\text { Quasi peak } \\
\mathrm{dBuV}\end{array}$ & $\begin{array}{c}\text { Average } \\
\mathrm{dBuV}\end{array}$ \\
\hline & & 100 & 90 \\
& $0,15 \leq \mathrm{f} \leq 0,5$ & 86 & 76 \\
$\mathrm{I} \leq 100 \mathrm{~A}$ & $0,5 \leq \mathrm{f} \leq 5$ & 90 & 80 \\
& $5 \leq \mathrm{f} \leq 30$ & decreases & decrease \\
& & 70 & 60 \\
\hline
\end{tabular}

The first environment is defined as environment that includes domestic premises. It also includes establishments directly connected without intermediate transformers to a low voltage power supply network which supplies buildings used for domestic purposes.
The second environment is defined as environment that includes all establishments other than those directly connected to a low voltage power supply network, which supplies buildings used for domestic purposes.

The mains power network of the chamber is filtered, thus providing clean power source without high frequency disturbances.

TABLE III

LIMITS FOR ELECTROMAGNETIC RADIATION DISTURBANCE IN 3M ANECHOIC CHAMBER

\begin{tabular}{|c|c|c|c|}
\hline $\begin{array}{c}\text { Frequency } \\
\text { band } \mathrm{MHz}\end{array}$ & $\begin{array}{c}\text { Category C1 } \\
\mathrm{dBuVi} / \mathrm{m}\end{array}$ & $\begin{array}{c}\text { Category C2 } \\
\text { Quasi peak } \\
\mathrm{dBuV} / \mathrm{m}\end{array}$ & $\begin{array}{c}\text { Quasi peak } \\
\mathrm{dBuV} / \mathrm{m}\end{array}$ \\
\hline $30 \leq \mathrm{f} \leq 230$ & 40 & 50 & 60 \\
\hline $230 \leq \mathrm{f} \leq 1000$ & 47 & 57 & 70 \\
\hline
\end{tabular}

\section{III.MEASUREMENT SETUP}

Shielded chamber also prevents the outside world radiated electromagnetic disturbances, such as radio and TV broadcasts, various wireless communication etc., influence on the measurements inside the chamber.

Matrix converter consists of power module with IGBT switches, digital signal processing unit (DSP), field programmable gate array (FPGA) and personal computer (PC) to control converters performance. The matrix converter is loaded with resistive load- rheostats. Test setup, including matrix converter and all control equipment (FPGA, DSP, PC) is shown in Fig. 1

Converter and auxiliary equipment are placed on wooden table $0.8 \mathrm{~m}$ above conductive ground and $0.4 \mathrm{~m}$ next to vertical conductive plate during conducted emission measurements. Measurements are carried out using line impedance stabilization network (LISN) ESH2-Z5, and EMI analyzer ESIB26 according to procedures stated in CISPR 16-1 and CISPR 11 [4],[5]. Main objective of LISN is to stabilize power distribution network impedance to $50 \Omega$ in frequency range $150 \mathrm{kHz}$ to $30 \mathrm{MHz}$, thus providing no effect delivering power on $50 \mathrm{~Hz}$ industrial frequency to matrix converter, and feed high frequency disturbances, created by matrix converter, into EMI analyzer.

Measurements are carried out in frequency range $150 \mathrm{kHz}-$ $30 \mathrm{MHz}$. LISN is placed $0.8 \mathrm{~m}$ far from converter, other metallic structures are at least $0.8 \mathrm{~m}$ far from device under testmatrix converter.

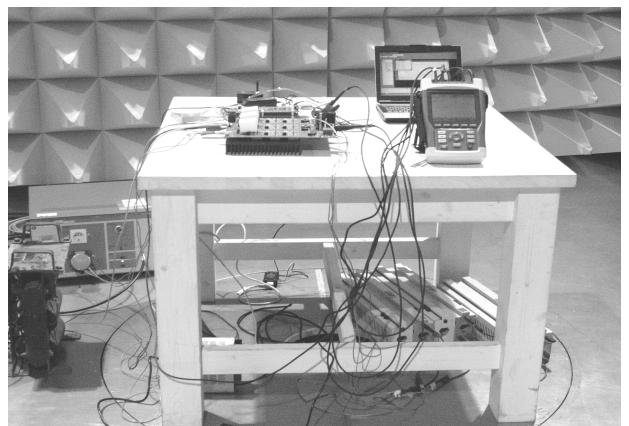

Fig.1. Conducted emission measurement setup at Latvia Electronic Equipment Testing Center semianechoic chamber. 
Converter and auxiliary equipment are placed on wooden turntable $1 \mathrm{~m}$ above conductive ground in a $3 \mathrm{~m}$ distance away from measuring antenna during radiated emission measurements. Measurements are carried out using logperiodic antenna HL562 and analyzer ESIB26 in frequency range $30 \mathrm{MHz}-3 \mathrm{GHz}$.

\section{MEASUREMENT AND TROUBLESHOOTING RESULTS}

\section{A. Conducted emissions}

Matrix converter conducted emission measurements were carried out under various operational conditions to detect the worst condition- the largest emissions, and locate the sources of disturbance and their characteristic:

- Load was varied from $0-3 \mathrm{~kW}$;

- Matrix converter power stage was disconnected from mains network, maintaining IGBT driving and DSP, FPGA operation;

- DSP and FPGA was disconnected maintaining IGBT drivers DC-DC power supply operation.

Disturbance voltage are measured on all three lines and neutral, with connected and disconnected grounding, as stated in CISPR 16-1 and CISPR 11 standards. Measurements carried out with quasi peak (QP) and average (AV) detectors. Measurement results are produced in graphs, containing quasi peak and average detector measurements and limit lines for quasi peak and average measurements.

Load variation has no impact on conducted emission performance. Measurement results are shown in Fig.2 matrix converter tested at $3 \mathrm{~kW}$ load.

To identify EMI sources more closely, LISN was disconnected from mains network, thus avoiding disturbances created in process of IGBT switching.

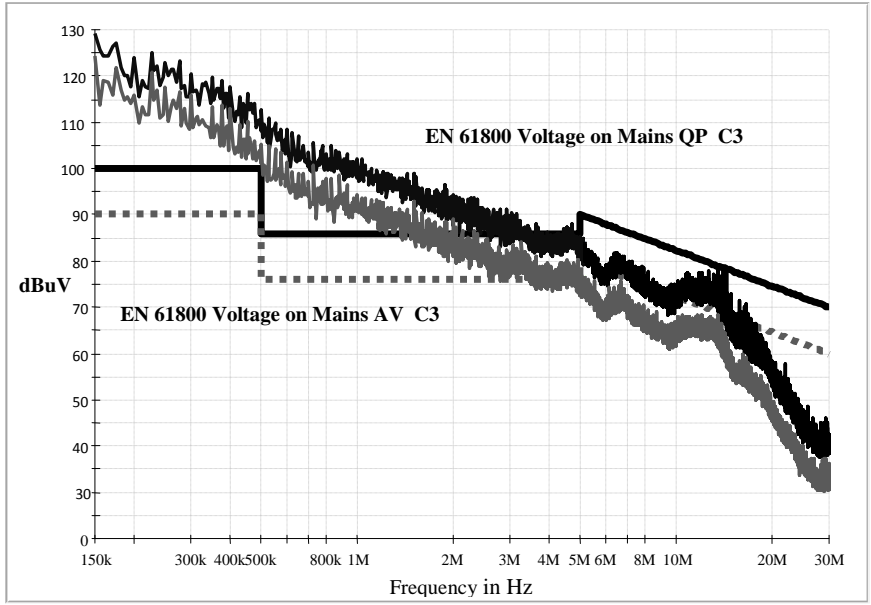

Fig.2. Conducted emissions, matrix converter loaded 3kW (black- quasi peak detector, gray- average detector measurements)

Measured disturbance amplitude has decreased drastically and character changed, showing harmonics of pulse width modulation (PWM) $65 \mathrm{kHz}$, but they are still too high to comply with $\mathrm{C} 1$ category device limits. These disturbances are created by IGBT gate drivers and gate driver's power supplies, also DSP and FPGA are part of emission source. Results are shown in Fig.3. The harmonics of $65 \mathrm{kHz}$ shows that in this test setup configuration, main emission source is IGBT gate driver who generates high $d v / d t$ slopes.

To verify this statement matrix converter was tested with disconnected DSP and FPGA auxiliaries, thus providing no input signal for IGBT gate drivers, so the EMI generated by gate drivers are eliminated. Actually, in this configuration DCDC converters for gate drivers are the only part of matrix converter working, thereby EMI source.

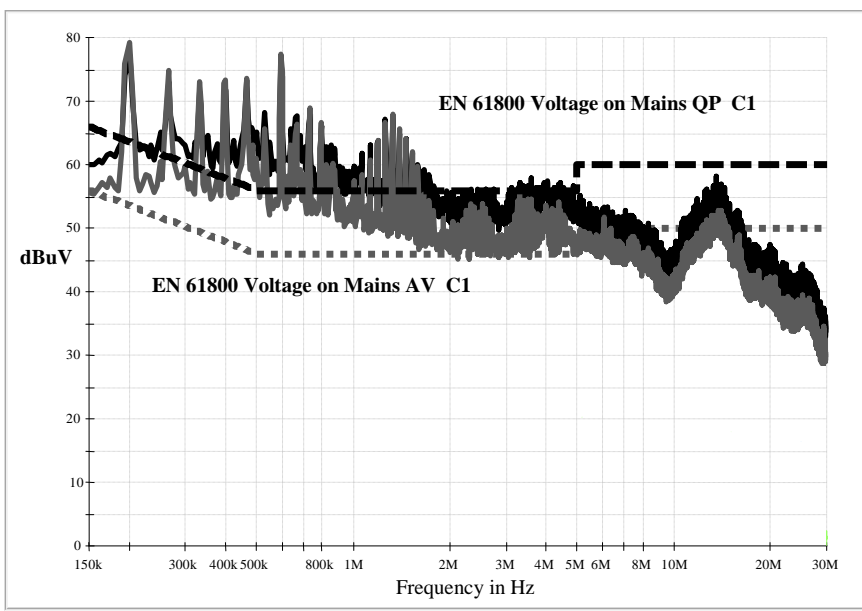

Fig.3. Conducted emissions, matrix converter disconnected from mains network (black- quasi peak detector, gray- average detector measurements).

The results are shown in Fig.4. Evidently emissions have decreased in range up to $1 \mathrm{MHz}$ and character of emissions has changed. But in frequency range over $1,5-5 \mathrm{MHz}$ emission level has increased do to load condition change of DC-DC converters which are used to drive IGBT's.

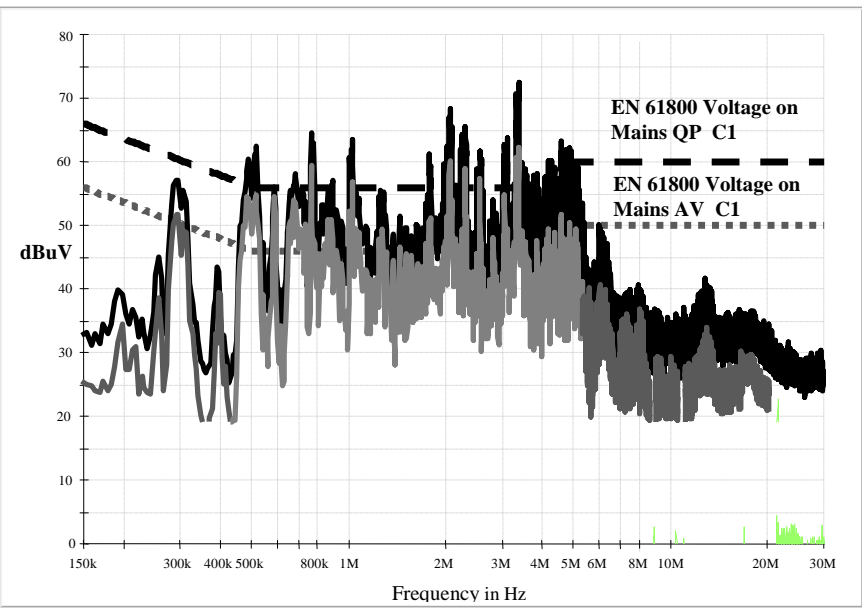

Fig.4. Matrix converter disconnected from mains network and disconnected from DSP and FPGA (black- quasi peak detector, gray- average detector measurements).

\section{B. Radiated emissions}

Matrix converter radiated emission measurements were carried out in various configurations, to allocate source of EMI. The same as in conducted emission measurements, load variation had no effect on radiated disturbance. Measured 
radiated emissions are shown in Fig.5, matrix converter are

To verify IGBT's switching influence on radiated disturbances, matrix converter was disconnected from mains network, continuing operate IGBT gate drivers and DSP, FPGA, PC.

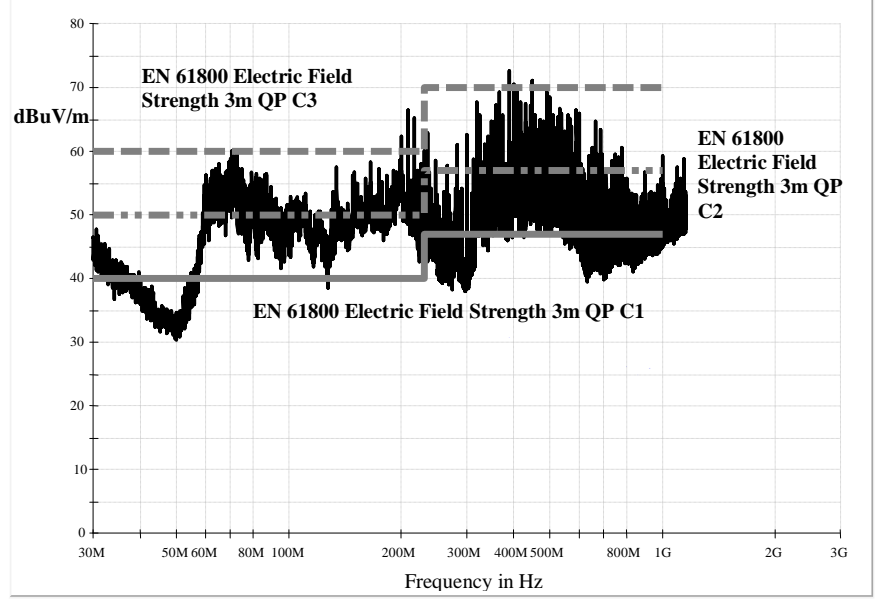

Fig.5. Radiated emissions, matrix converter loaded 3kW (Peak detector measurements)

Emissions are displayed in Fig.6. Emissions have decreased in frequency range of 50-100MHz.

Further, IGBT gate driver's power supplies (DC-DC converters) were disconnected, disabling all the activities on matrix converter. In this configuration only control and processing units were left on, so measured disturbances were created by FPGA and DSP, PC.

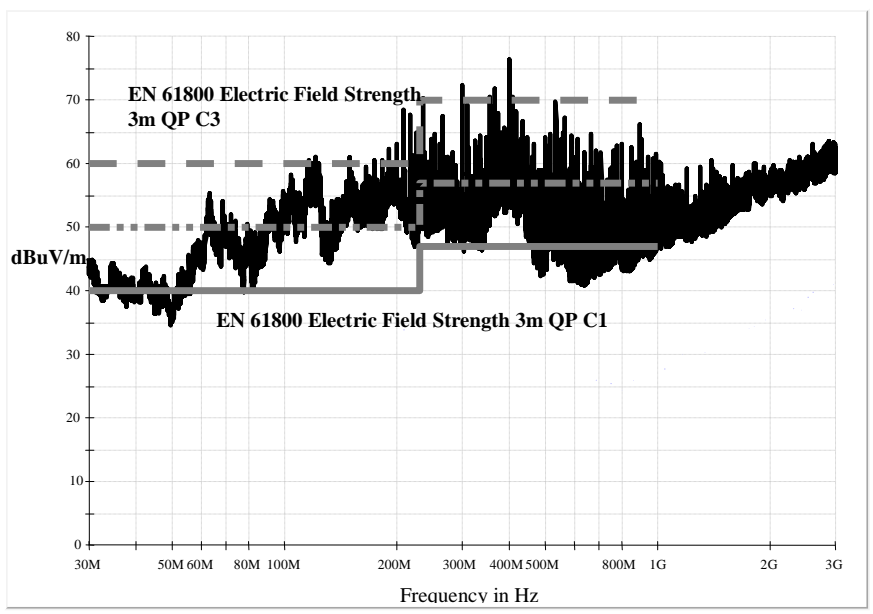

Fig.6. Radiated emissions matrix converter disconnected from mains network (Peak detector measurements).

Results are displayed in Fig.7. Measured disturbances have decreased in frequency range of $30 \mathrm{MHz}-150 \mathrm{MHz}$. In range of $150 \mathrm{MHz}-1 \mathrm{GHz}$ nothing has changed, indicating radiated electromagnetic disturbances created by signal processing and computing units- including FPGA, DSP and PC. These units contains high frequency clock sources and have long interconnection cables acting like effective antennas, hence operated under $3 \mathrm{~kW}$ load.

cable lengths is comparable with wave lengths created by these high frequency sources.

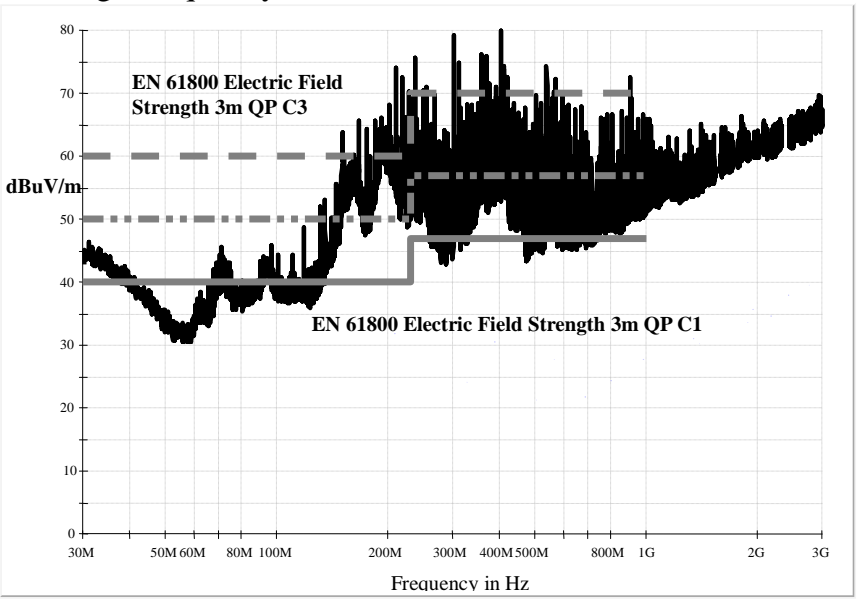

Fig.7. Radiated emissions DSP, FPGA and PC emitted disturbances (Peak detector measurements).

\section{V.Troubleshooting Procedure to DEVElop COMPLIANT DEVICE}

Upper stated measurement and troubleshooting methods evaluate matrix converter emissions, verifying its compatibility to standards, and also these studies gives useful information on sources of disturbances. However, it is not enough to decide what kind of filter elements and where to install, and how to change printed circuit board of power module, and how to deal with variety of modules and their interconnections.

Power drive systems are high power (100-10000W) and EMC problems can be really hard to solve, especially when the power supply cord, a key element in the problem, is considered. That is usually a problem for the high frequency (HF), very high frequency (VHF) and ultra high frequency (UHF) range. To find a theoretical model for a solution is usually difficult, if not possible. Special interest is devoted to:

1. common mode EMI can be radiated by that cable (typically in the $30-1000 \mathrm{MHz}$ range);

2. differential and/or common mode noise conducted in that cable $(9 \mathrm{kHz}-30 \mathrm{MHz})$ to the LISN (Line Impedance Stabilization Network).

In any way, it is usual, to spend a lot of additional time with first prototype trying:

- to reduce EMI to comply regulations in specialized EMC laboratory, during precompliance and troubleshooting measurements;

- evaluating the real need of included EMI components to reduce cost and/or size.

Those problems must be understood from a theoretical point of view but some experimental analysis is imperative to be able to find a solution in a reasonable time schedule.

The experimental analysis and further evaluation of the matrix converter design can be afforded with the following instruments/accessories: 
- Radio frequency (RF) current probes to measure common and differential mode currents in power supply cord and other inter connection cables for the HF/VHF/UHF range;

- Radio frequency (RF) voltage probes to measure voltages on PCB terminals and directly on inputs and outputs of integrated circuits in $\mathrm{HF} / \mathrm{VHF} / \mathrm{UHF}$ range;

- Near field probes to find culprits in the design;

- Spectrum analyzer;

- Scope with 50ohms input and 300-1000MHz bandwidth;

- EMC components (e.g. kits) for the evaluation.

When used in a good way, it will be possible:

- to fix EMC radiated and conducted problems;

- to find the source of a problem in the cables;

- to evaluate the need of a component (a ferrite, a capacitor, a snubber, etc);

- to compare different values or configurations of a component/section and

- to analyze in more details the matrix converter EMI behavior with different load and supply voltage conditions, not limited only by quasi stationary condition.

The stepwise procedure to analyze the design is, basically:

STEP 1.- Design a first prototype from your experience, application notes and engineering reports.

STEP 2.- Locate the usual EMI culprits [6]-[7]. Design to avoid them (e.g. layout, technology, etc) and include EMC components to be able to evaluate their need (e.g. snubbers, decoupling capacitors in DC bus-GND path, etc).

STEP 3.- Design PCB including headers for all the EMC components to be evaluated: input filter components, X capacitor(s), Y capacitor(s), ferrites, etc. Do not forget to include headers for the power devices (surely they will be damaged in some of the tests).

STEP 4.- Optional: if you are troubleshooting an existing design, it will be useful to know the results of the certification or EMC laboratory, to identify the frequencies where the problems arises.

STEP 5.- Optional: you can start the analysis with the prototype WITHOUT any EMC component. You will add them as needed in next steps.

STEP 6.- Using the current probes in differential and common modes, visualize the frequency response for currents in the $30 \mathrm{MHz}-1 \mathrm{GHz}$ range applying probes to all input and out put cables of matrix converter including power cables, communication and control cables. Measure the response with the power supply switched OFF to identify your background noise if measurements are not carried out in shielded room. Also switch OFF different modules (power module, signal processing modules, low voltage DC power supply modules, etc.) to locate the source of emissions. Use the maxhold function of the analyzer. Specially consider the common mode currents, because they will be the culprit for radiated problems in that frequency range $30 \mathrm{MHz}-1 \mathrm{GHz}$. If problem arises in some frequency range, memorize the trace and visualize in the screen. Try to locate the culprit with the near field probes. If found, try to change as appropriated or add EMC components while looking for the measure of the current probe in the spectrum analyzer. You must compare the real time measure with the saved trace before. The process will be finished when measured current will be small enough to comply with limits defined in EMC standards (for radiated emissions on cables with length comparable to radiated wave lengths- good $<30 \mu \mathrm{A}$, better $<8 \mu \mathrm{A})$.

STEP 7.- Repeat step 6 for the $9 \mathrm{kHz}-30 \mathrm{MHz}$ range looking for the conducted problems (common mode and differential mode). Here, the input filter will be the key element.

Important: the input filter is usually designed for frequency range $150 \mathrm{kHz}$ to $30 \mathrm{MHz}$ but, it must be optimized for $\mathrm{HF} / \mathrm{VHF}$ to reduce radiated problems in frequency range up to $1 \mathrm{GHz}-3 \mathrm{GHz}$.

Usually, in one or two iterations, the design can be made compatible with regulations and some of the EMC key components (capacitors, ferrites, chokes, etc) could be removed if they are not really needed.

A secondary benefit of troubleshooting process is education for future designs.

\section{CONCLUSIONS}

The main objective of this study was to obtain data about matrix converter emitted electromagnetic disturbances in frequency range of $150 \mathrm{kHz}-1 \mathrm{GHz}$ from point of view of IEC 61800-3 EMC standard and to locate the sources of undesirable emissions using measurement techniques stated in EMC standards to verify power electronics EMC performance. In low frequency range $150 \mathrm{kHz}-30 \mathrm{MHz}$ conducted emissions were measured. Matrix converter emitted disturbances are load independent. The main source is IGBT commutation process that is responsible for $130 \mathrm{dBuV}$ high disturbances prohibiting to connect matrix converter to mains network, following the EMC directive. Disturbances are also created by IGBT gate drivers and DC-DC converters that are provided for IGBT gate drivers power supply. Thereby generated disturbances are high enough to fail $\mathrm{C} 1$ limit line.

Radiated emissions were measured in frequency range $30 \mathrm{MHz}-1 \mathrm{GHz}$. As like as during conducted measurements, load of matrix converter has no considerable impact on emitted disturbances. IGBT commutation, IGBT gate drivers and their power supplies emissions are in range of $30 \mathrm{MHz}-$ $150 \mathrm{MHz}$ and high enough to fail to comply with C3 limits. But the highest emission levels are emitted from control and processing units connected to matrix converter in range of $150 \mathrm{MHz}-1 \mathrm{GHz}$. Radiated emissions are high enough to prohibit connecting matrix converter to distribution grid. 
To lower conducted emissions it is necessary to suppress sources of disturbance. The easiest way to achieve it is apply filter at matrix converter input, which is designed basing on input common and differential mode currents. The second choice is to damp the noise sources separately by means of using separate filters for DC-DC converters, increase IGBT gate control pulse rise and fall times and use damping circuits to deal with IGBT commutation process created byproducts, what is the next step in matrix converter development and further issue of research.

The second objective was to describe alternative method to verify matrix converter electromagnetic compatibility, troubleshoot and develop matrix converter design, using low cost equipment available in almost every electronics laboratory.

\section{REFERENCES}

[1] W.Teulings, J.L. Schanen, J. Roudet. A new technique for spectral analysis of conducted noise of a SMPS including interconnects. 28th Annual IEEE Power Electronics Specialists Conference, USA 1997, p1516-1521

[2] Wei Zhang, Michael T. Zhang, Fred C. Lee, et al. Conducted EMI analysis of a boost PFC circuit. 12 $2^{\text {th }}$ Annual IEEE Applied Power Electronics Conference and Exposition, USA, 1997, p223-229

[3] IEC 61800-3 Standard. Adjustable Speed Electrical Power Drive Systems - Part 3: EMC Requirements and specific test methods

[4] CISPR 16-1 Standard. Specification for radio disturbance and immunity measuring apparatus and methods - Part 1-1: Radio disturbance and immunity measuring apparatus - Measuring apparatus

[5] CISPR 11 Standard. Industrial, scientific and medical equipment- Radiofrequency disturbance characteristics- Limits and methods of measurement

[6] Power Integrations, AN-15 TOPSwitch Power Supply Design Techniques for EMI and Safety, April 2005.

[7] Daryl Sugasawara and Jens Paetau: Safety, EMI and RFI Considerations, Application Note 42007, Fairchild, June 1996.

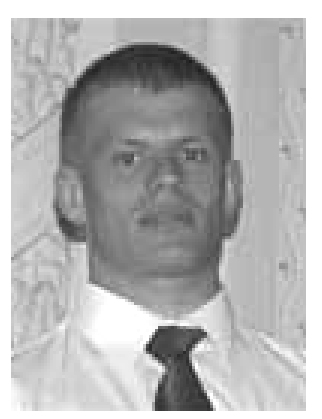

Gundars Asmanis received the B.Eng. and M.Eng. degrees from Riga Technical University, Riga, Latvia, in 2009. His research interest includes EMI/EMC in power electronic systems, electronics, telecommunication systems, electrostatic discharge radiated fields, lightning created electromagnetic fields and electromagnetic pulse.

$\mathrm{He}$ is currently a Lecturer assistant in the faculty of Electrical Engineering, Riga Technical University (Electromagnetic Compatibility). He is also general engineer at Latvia Electronic Equipment Testing Center LEITC, Riga Latvia, and research assistant at ESED center, Riga Latvia.

Department of Power and Electrical Engineering, Riga Technical University, Kronvalda blvd 1-324, Riga,LV-1010, Latvia.

E-mail: asmanisgundars@inbox.lv

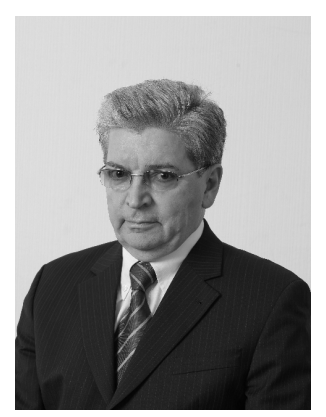

Leonids Ribickis is a professor, Vice Rector for Science of Riga Technical University. Received Dipl.El.Ing. qualification in 1970 (Riga Polytechnic Institute), in 1980 received PhD. In Belorussian Polytechnic Institute and in 1994 - Dr.Habil.Sc.ing. at RTU.

Director of Institute of Industrial Electronics and Electrical Drives, Faculty of Power and Electrical Engineering, Riga Technical University.

Research interest $\mathrm{A} / \mathrm{C}$ regulated drive systems, A/C special electric machines and their constructions, converters of semi-conductor electric energy and methods of control, piezoelectric converters, power electronics EMC and artificial blood-vessels.

Department of Power and Electrical Engineering, Riga Technical University, Kalku 1-217, Riga, LV-1010, Latvia.

E-mail: leonids.ribickis@rtu.lv

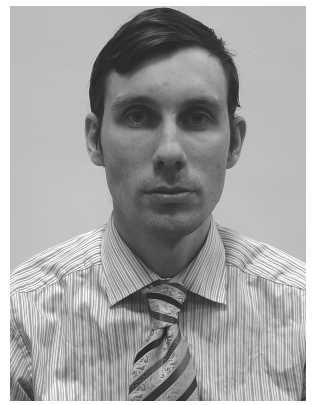

Vladimirs Novikovs received the M.Sc.Ing. degrees from Riga Technical University, Riga, Latvia, in 2005.

His research interests are EMC impact on telecommunication equipment and systems. He is currently a general manager in the Latvian Electronic Equipment Testing Centre and makes research projects for Riga Technical University

Department of Electronics and Telecommunication, Riga Technical University, Azenes 12-7, Riga, LV-1034, Latvia.E-mail: vladimirs@leitc.lv 